\title{
Prevalence of Anaemia in India and Strategies for Achieving Sustainable Development Goals (SDG) Target
}

\author{
PREMA RAMACHANDRAN and K KALAIVANI* \\ Nutrition Foundation of India, C 13 Qutab Institutional Area, New Delhi 110 016, India
}

(Received on 18 June 2018; Accepted on 03 July 2018)

\begin{abstract}
India recognised anaemia as a major public health problem and initiated national programmes for combating anaemia in pregnant women and pre-school children in 1970. It is important to find out the coverage and impact of these programmes on prevalence of anaemia and also assess the prevalence of anaemia across all groups of population.In the last two decades, National Family Health Survey (NFHS) 2, 3, 4, District Level Household Survey (DLHS) 2, 4 and Clinical Anthropometric and Biochemical component of Annual Health Survey (AHS CAB) had assessed coverage under antenatal care, anaemia control programme and estimated $\mathrm{Hb}$ levels in the survey population. Data from all these surveys were analysed. All surveys showed a slow improvement in coverage under antenatal care and IFA supplementation. There were no clear or consistent changes in mean $\mathrm{Hb}$ or in prevalence of anaemia in pre-school children, adolescent girls and pregnant women between NFHS 2, 3 and 4 at national or state level. DLHS 2 reported a higher prevalence of anaemia in all these three groups as compared to NFHS 2. Compared to DLHS 2 there was about $1 \mathrm{~g} / \mathrm{dL}$ increase in mean $\mathrm{Hb}$, a shift to the right in the distribution of $\mathrm{Hb}$ levels and a 15-20\% reduction in the prevalence of anaemia in DLHS 4 \& AHS CAB. But even in 201415 , a majority of Indians of all ages and both sexes were anaemic; the prevalence of anaemia ranged between $57.1 \%$ and 89.3\%. Prevalence of anaemia in India is very high across all groups. The three-pronged strategy of increasing iron intake in all households through dietary diversification and use of iron-fortified iodized salt, IFA supplementation to vulnerable groups, the testing and timely treatment of pregnant women with anaemia will be required to accelerate the pace of reduction in the prevalence of iron-deficiency anaemia and enable the country to achieve SDG target for the reduction in anaemia.
\end{abstract}

Keywords: Haemoglobin Levels; Prevalence of Anaemia; Dietary Diversification; Double Fortified Salt; 'Test And Treat' Strategy; SDG Target for Reduction in Anaemia

\section{Introduction}

India has been and continues to be a country with the highest prevalence of anaemia in the world. Being a country with a billion plus population, India is home to the largest number of anaemic people in the world (WHO 2015, Stevens et al., 2013). In India, the prevalence of anaemia is high because of:

- $\quad$ low overall dietary intake, poor iron and folic acid intake and poor bio-availability of iron in the phytate fibre-rich Indian diet resulting in widespread iron and folic acid deficiencies and;

- chronic blood loss due to infections such as malaria and hook worm infestations.
Data from surveys carried out by the National Nutrition Monitoring Bureau (NNMB 2003, 2012) show that even now vegetable intake and consequently iron and folic acid intake is low. Research studies have shown that iron deficiency is the most common micro-nutrient deficiency associated with anaemia, while folate deficiency and Vitamin B12 deficiency are ranked as the second and third most prevalent micro-nutrient deficiencies associated with anaemia. Infants born to anaemic mothers have low iron stores; the low iron content in milk and complementary foods result in a high prevalence of anaemia during infancy. Unmet needs of iron for growth during childhood and adolescence and in adolescent girls the onset of menstruation cause further rise in the prevalence of

*Author for Correspondence: E-mail: kalaivanikrishnamurthy@gmail.com 
anaemia. The increased demand for iron during pregnancy aggravates anaemia. It has been shown that dietary diversification including pulses, millets rich in iron, animal foods which contain haem iron with higher bio-availability and consumption of Vitamin C rich food stuffs like guava which increase iron absorption can result in improvement in haemoglobin content. Treatment of malaria and deworming in hook worm endemic areas can also improve $\mathrm{Hb}$ levels.

Epidemiological studies have shown that pregnant women, pre-school children and adolescent girls are the most vulnerable groups for anaemia and its adverse health consequences (Kalaivani 2009). Anaemia was recognized as a major public health problem in India leading to high maternal morbidity and mortality, low birth-weight and high infant mortality (Steer 2000, Sharma 2008, Kozhuki 2012). It has been shown to be associated with poor scholastic performance and increased susceptibility to infection in children, and easy fatigability and poor work capacity in adults. The National Nutritional Anaemia Prophylaxis Programme (NNAPP), aimed at iron and folic acid supplementation for pregnant women and pre-school children, was formulated in 1970 (MoH\&FW 1970). In 1991, the National Anaemia Control Programme (NACP) added the 'test, detect and treat' strategy for the management of anaemia in pregnant women (MoH\&FW 1989, 1991). In 2013 weekly iron-folic acid supplementation for school children across the country was initiated (MOH\&FW 2013).

In the last two decades, 6 national surveys had assessed coverage under anaemia control programmes and estimated $\mathrm{Hb}$ in vulnerable groups. Data from all these surveys showed that over time there was an improvement in access to antenatal care and coverage under IFA supplementation. Data from National Family Health Surveys (NFHS) surveys showed that there was no reduction in prevalence of anaemia between NFHS 2, 3 and 4. There was a reduction in prevalence of anaemia in District Level Household Survey (DLHS) 4 and Annual Health Survey Clinical Anthropometric Biochemical Component (AHS CAB) as compared to DLHS 2. It has been suggested that the lack of reduction in prevalence of anaemia in NFHS surveys could be due to the fact that Hemocue does not provide accurate estimation of $\mathrm{Hb}$ (Ramachandran 2017). In- depth analysis of data from all the six surveys may provide insights regarding the progress in the on-going programmes for anaemia control and the impact of these programmes in terms of improvement in $\mathrm{Hb}$. Based on the finding, an attempt can be made to define appropriate strategies to accelerate the pace of reduction in anaemia and achieve the SDG targets.

\section{Material and methods}

Between 1998-2015, National Family Health Survey (NFHS) 2, 3, 4, District Level Household Survey (DLHS) 2, 4 and Clinical Anthropometric and Biochemical component of Annual Health Survey (AHS CAB) had assessed coverage under antenatal care, anaemia control programme and estimated $\mathrm{Hb}$ levels. The unit-level data of NFHS 2, 3 and 4 (after deletion of personal identifiers) were obtained from the Demographic and Health Survey (DHS) Programme. The unit-level data were obtained from the International Institute for Population Sciences, Ministry of Health \& Family Welfare (MoHFW) for DLHS 2 and 4; data from AHS CAB were obtained from the MoHFW. The year in which these surveys were conducted, the states covered, groups in which $\mathrm{Hb}$ estimation was done and the method by which $\mathrm{Hb}$ was estimated is given in Table 1. Table 2, $3 \mathrm{~A}$ and $3 \mathrm{~B}$ provide information on total number of persons belonging to different age/sex groups for whom valid $\mathrm{Hb}$ data was available in different surveys. Cut-off values for $\mathrm{Hb}$ level for different age sex groups is given in Table 4. Data from all these surveys were analysed for coverage under antenatal care and IFA supplementation, mean and frequency distribution of $\mathrm{Hb}$ and prevalence of anaemia. SPSS software (IBM SPSS Statistics version 16.0, NY, USA) was used for data analysis.

\section{Results}

\section{Time Trends in $\mathrm{Hb}$}

Mean $\mathrm{Hb}$ values and time trends in the prevalence of anaemia at national level in under-five year (U5) under-three year (U3) children, pregnant (PG) and non-pregnant adolescent girls (NP G), pregnant women (PW) non-pregnant women (NPW) and men (M), based on data from NFHS 2, 3, and 4, are shown in Figs. 1 and 2.

The mean $\mathrm{Hb}$ values in NFHS series in all pre- 
Table 1: Summary of National Surveys for Anaemia conducted in India

\begin{tabular}{|c|c|c|c|c|}
\hline $\begin{array}{l}\text { Name of the } \\
\text { survey }\end{array}$ & $\begin{array}{l}\text { Years } \\
\text { conducted }\end{array}$ & States covered & Population covered & $\begin{array}{l}\text { Method of } \mathrm{Hb} \\
\text { estimation }\end{array}$ \\
\hline NFHS 2 & $1998-99$ & $\begin{array}{l}\text { Only done in states \& NCT Delhi } \\
\text { (UTs not covered) }\end{array}$ & $\begin{array}{l}\text { U3 children, ever married women } 15-49 \text { yrs } \\
\text { (pregnant \& non pregnant) }\end{array}$ & Hemocue \\
\hline NFHS 3 & 2004-05 & $\begin{array}{l}\text { Only done in states \& NCT Delhi } \\
\text { (UTs not covered) }\end{array}$ & $\begin{array}{l}\text { U } 5 \text { children, } 15-49 \text { yrs women } \\
\text { (pregnant \& non pregnant), } 15-54 \text { yr men }\end{array}$ & Hemocue \\
\hline NFHS 4 & 2015 & All states and UTs & $\begin{array}{l}\text { U-5 children } 15-49 \text { yrs women (pregnant \& non } \\
\text { pregnant), men (15-54yr) }\end{array}$ & Hemocue \\
\hline DFHS 2 & $2002-04$ & All states and UTs & $\begin{array}{l}\text { Preschool children 0-4yr Adolescent girls 10-19 } \\
\text { yrs Pregnant women }\end{array}$ & $\begin{array}{l}\text { cyanmethaemo- } \\
\text { globin }\end{array}$ \\
\hline AHS-CAB & 2015 & $\begin{array}{l}\text { Assam, Bihar, Chhattisgarh, } \\
\text { Jharkhand, Madhya Pradesh, } \\
\text { Odisha, Rajasthan, Uttar Pradesh } \\
\text { and Uttarakhand }\end{array}$ & All age group both sexes & $\begin{array}{l}\text { cyanmethaemo- } \\
\text { globin }\end{array}$ \\
\hline DLHS 4 & $2013-14$ & $\begin{array}{l}\text { All other states \& UTs (survey } \\
\text { not done in Gujarat, Jammu \& } \\
\text { Kashmir, Lakshadweep) }\end{array}$ & All age groups and both sexes & $\begin{array}{l}\text { cyanmethaemo- } \\
\text { globin }\end{array}$ \\
\hline
\end{tabular}

Table 2: No of persons with valid Hb from NFHS2, 3, 4 and DLHS2

\begin{tabular}{lcccccccc}
\hline Group & U 5 boys & U 5 girls & 10-14 girls & $15-19$ boys & $15-19$ girls NP & PW & $20-39$ Men & 20-39 women \\
\hline NFHS2 & U3 12968 & U3 11757 & NA & NA & 2682 & 2749 & NA & 23160 \\
NFHS 3 & 18884 & 16960 & NA & 153 & 2144 & 3892 & 20510 & 39234 \\
NFHS4 & 108986 & 100309 & NA & 18806 & 116564 & 21730 & 60290 & 388741 \\
DLHS 2 & 90409 & 82984 & 91520 & NA & 73069 & 21212 & NA & NA \\
\hline
\end{tabular}

Table 3A: No of persons with valid Hb in DLHS 4 \& AHS CAB

\begin{tabular}{lccccccccc}
\hline Group & U 5 boys & U 5 girls & 5-9 boys & 5-9 girls & $10-14$ boys & 10-14 girls & 15-19 boys & $15-19$ girls NP & $15-19$ PG \\
\hline DLHS4 & 26701 & 24804 & 40891 & 37316 & 45663 & 43461 & 44816 & 46459 & 1056 \\
AHS CAB & 40204 & 36202 & 60057 & 54857 & 71134 & 64960 & 61202 & 61461 & 1024 \\
\hline
\end{tabular}

Table 3B: No of persons with valid Hb in DLHS 4 \& AHS CAB

\begin{tabular}{lccccccc}
\hline Group & PW 20-39 & $20-39$ Men & 20-39 women & $40-59$ men & 40-59 women & $\leq 60$ men & $\leq 60$ women \\
\hline DLHS4 & 8459 & 153927 & 198737 & 116463 & 136855 & 61706 & 63089 \\
AHS CAB & 12911 & 159970 & 189158 & 112394 & 126395 & 58012 & 57236 \\
\hline
\end{tabular}

Table 4: Cut-off values of $\mathrm{Hb}$ for anaemia

\begin{tabular}{ll}
\hline Group & $\begin{array}{l}\text { Cut off value of } \\
\text { Hb for anaemia }\end{array}$ \\
\hline Men $\geq 20$ yrs & $13 \mathrm{~g} / \mathrm{dL}$ \\
Women $\geq 20$ yrs & $12 \mathrm{~g} / \mathrm{dL}$ \\
Pregnant women & $11 \mathrm{~g} / \mathrm{dL}$ \\
Children (boys and girls) (5-9yr) & $11.5 \mathrm{~g} / \mathrm{dL}$ \\
Preschool children (boys and girls 0-4 yr) & $11 \mathrm{~g} / \mathrm{dL}$ \\
Adolescent (boys and girls 10-19) & $12 \mathrm{~g} / \mathrm{dL}$ \\
\hline
\end{tabular}

school children, adolescent girls and pregnant women were higher and the prevalence of anaemia was lower as compared to DLHS 2 and surveys carried out by National Nutrition Monitoring Bureau (NNMB 2003). There were no clear or consistent changes in mean $\mathrm{Hb}$, frequency distribution of $\mathrm{Hb}$, or prevalence of anaemia between NFHS 2, 3, and 4 at the national or state level. In all the three NFHS surveys there were large inter-state variations in the prevalence of anaemia in all three vulnerable groups. 


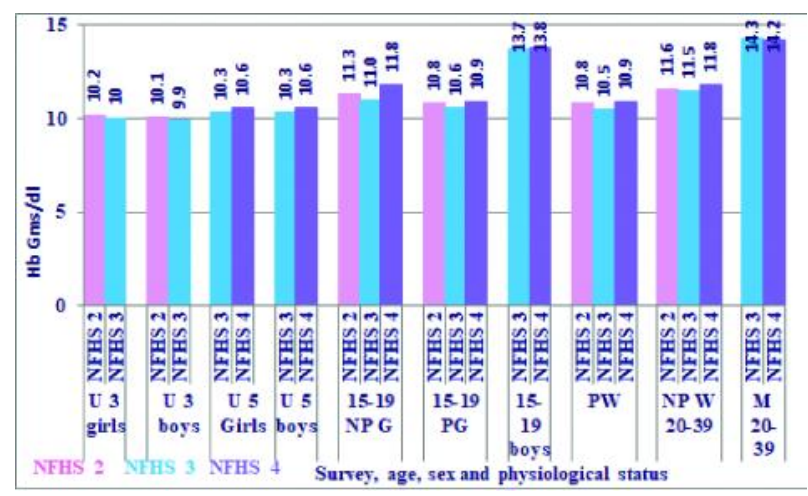

Fig. 1: Mean Hb in vulnerable groups (NFHS2, 3 and 4). U3 under-3 year children, U5 under-5 year children, NP G non-pregnant girls, PG pregnant girls, PW pregnant women, NP W non-pregnant women, M men

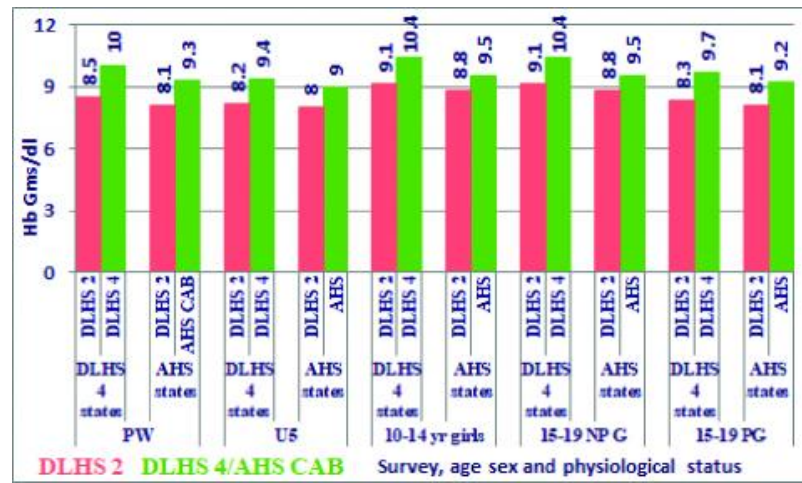

Fig. 3: Mean $\mathrm{Hb}$ in vulnerable groups (DLHS 2, 4 and AHS CAB). U5 under-5 year children, NP G non-pregnant girls, PG pregnant girls, PW pregnant women

Compared to DLHS 2, there was an improvement in mean $\mathrm{Hb}$ levels (Fig. 3), and reduction in the prevalence of anaemia in DLHS 4 and AHS CAB (Fig. 4).

In all the three groups there was a shift to the right in the frequency distribution of $\mathrm{Hb}$ in DLHS4 and AHS CAB as compared to DLHS 2 (Figs. 5, 6 and 7). The shift to the right was highest in pregnant women, lower in pre-school children and least in adolescent girls. In each group the shift to the right was more in DLHS states than in AHS states.

There were substantial inter-state differences in the time trends of the prevalence of anaemia in pregnant women (Fig. 8). Both in DLHS and AHS states, improvement in $\mathrm{Hb}$ levels was higher in pregnant women as compared to the other two groups.

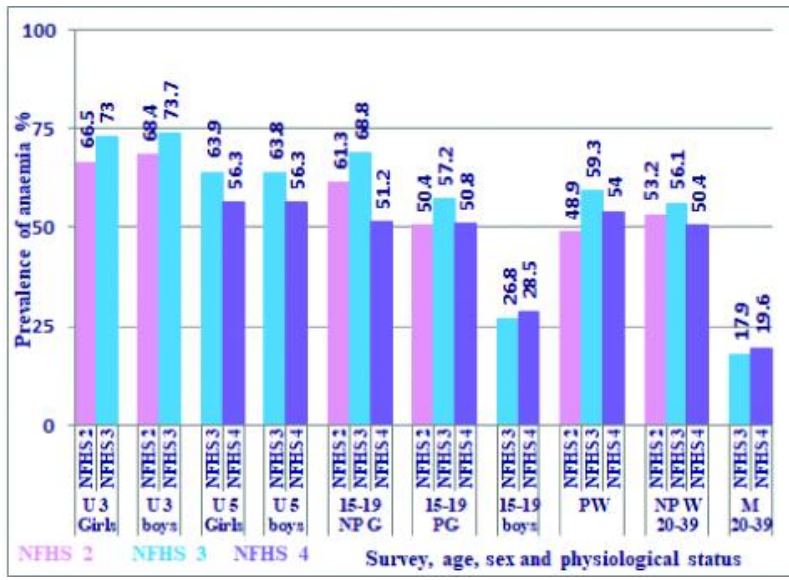

Fig. 2: Prevalence of anaemia in vulnerable groups (NFHS 2, 3 and 4). U3 under-3 year children, U5 under-5 year children, NP G non-pregnant girls, PG pregnant girls, PW pregnant women, NP W non-pregnant women, $M$ men

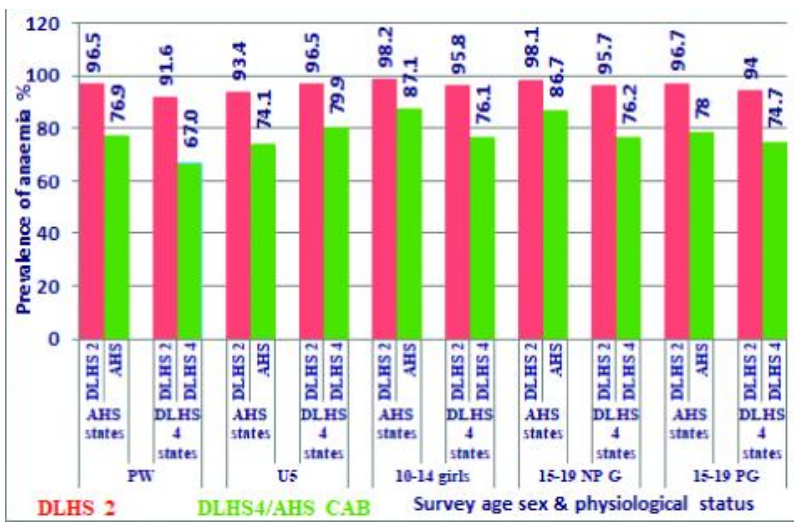

Fig. 4: Prevalence of anaemia in vulnerable groups (DLHS2, 4 and AHS CAB). U5 under-5 year children, NP G non-pregnant girls, PG pregnant girls, PW pregnant women

\section{Current Status}

\section{Hb Status}

DLHS 4 and AHS CAB together provide the nationwide data on $\mathrm{Hb}$ levels and prevalence of anaemia across all states and all age, sex and physiological groups (Fig. 9). The mean $\mathrm{Hb}$ values in the various age, sex and physiological groups ranged between 9.0-11.6g/dL. Mean Hb levels across all age sex and physiological groups were higher in DLHS 4 states as compared to AHS states (Fig. 9).

Mean $\mathrm{Hb}$ levels were lowest in the growing preschool children. There was a progressive increase in 

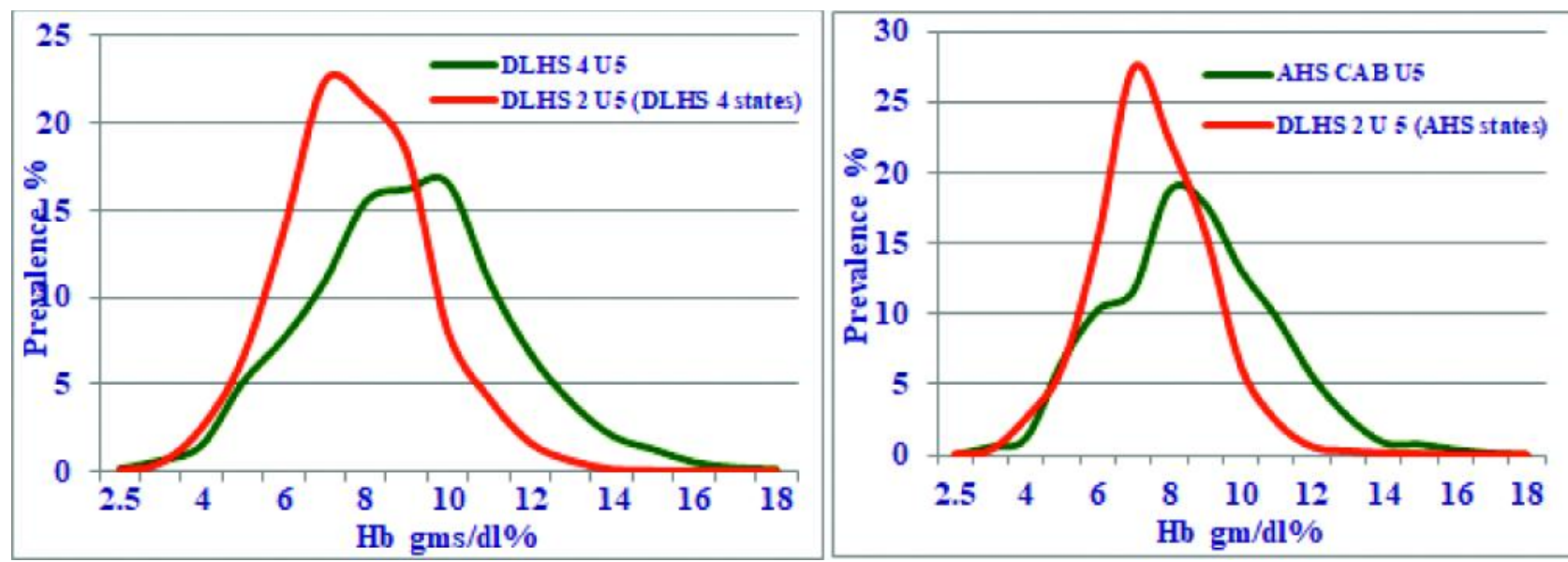

Fig. 5: Frequency distribution of Hb in U 5 DLHS $24 \&$ AHS. U5 under five yr children (Copyright permission obtained from NFI Bulletin)
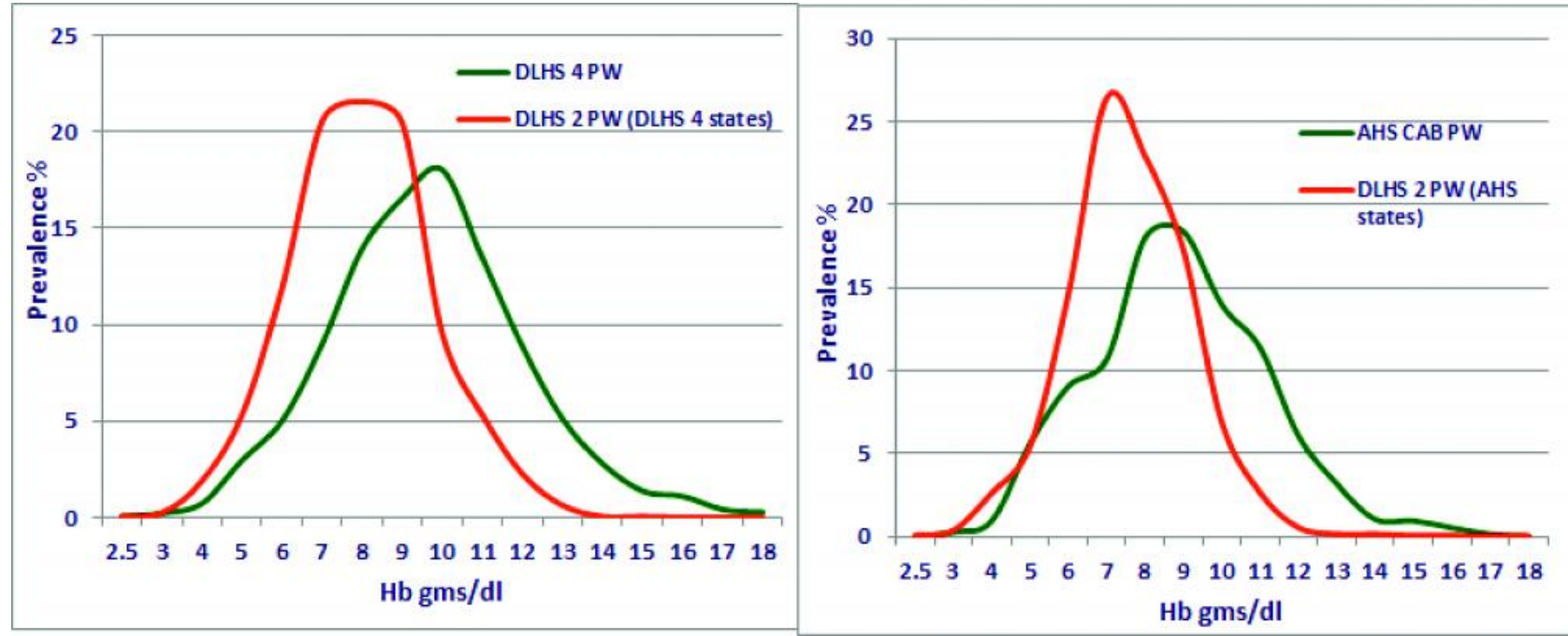

Fig. 6: Frequency distribution of $\mathrm{Hb}$ in PW (DLHS 2, 4 \& AHS). PW pregnant women (Copyright permission obtained from NFI Bulletin)
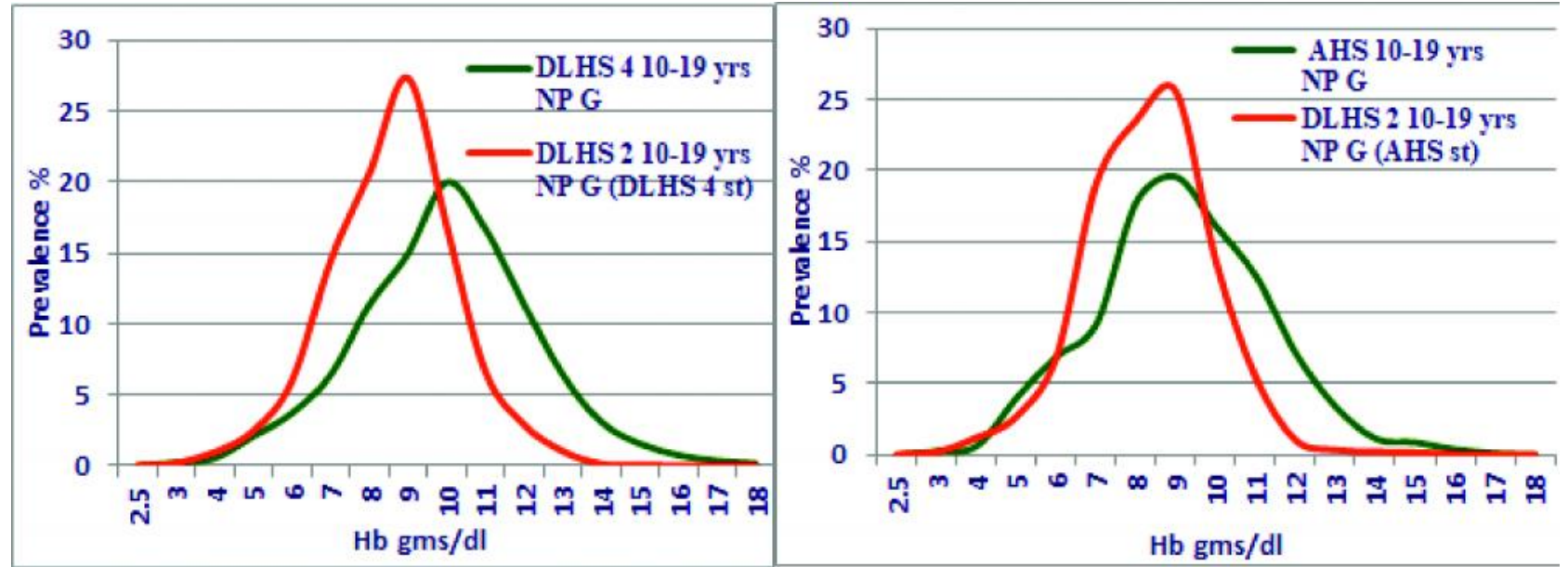

Fig. 7: Frequency distribution of $\mathrm{Hb}$ in 10-19 yr girls (DLHS 2, 4 \& AHS) NP G non-pregnant girls (Copyright permission obtained from NFI Bulletin) 


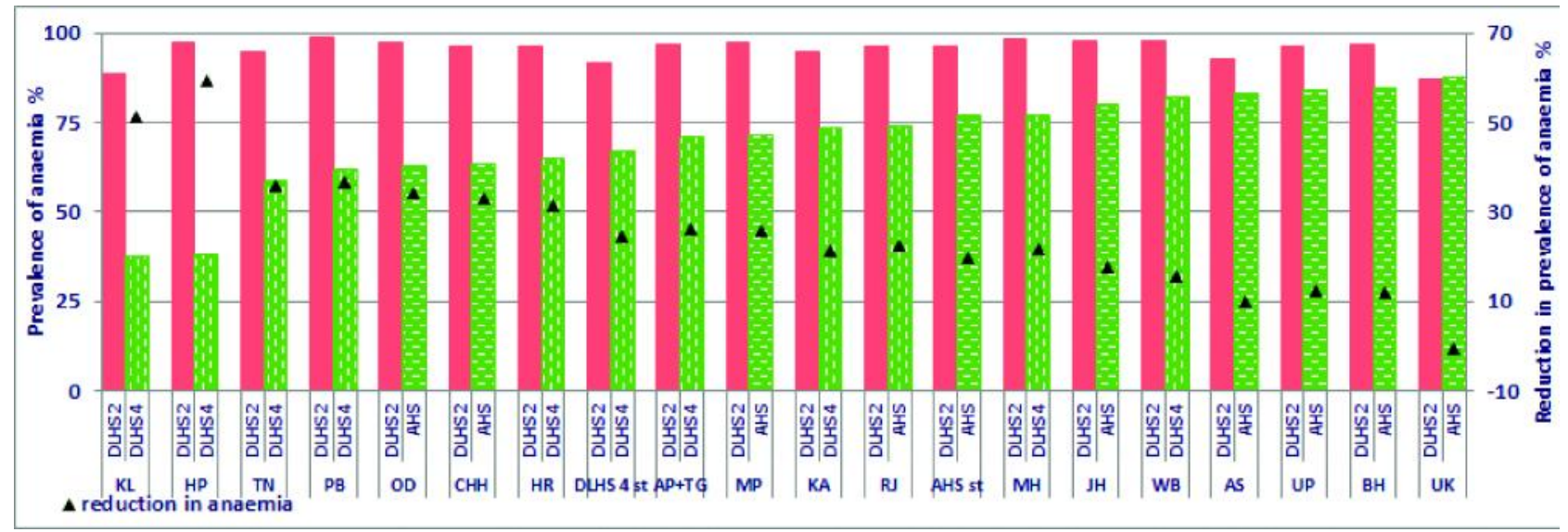

Fig. 8: Inter-state differences in prevalence of anaemia in PW (DLHS2, 4 \& AHS). Kerala (KL), Himachal Pradesh (HP), Tamil Nadu (TN), Punjab (PB), Odisha (OD), Chhattisgarh (CHH), Haryana (HR), District Level Household Survey4 states (DLHS 4 st) Andhra Pradesh combined (AP+TG), Madhya Pradesh (MP), Karnataka (KA), Rajasthan (RJ), Annual Health Survey states (AHS st) Maharashtra (MH), Jharkhand (JH), West Bengal (WB) Assam (AS), Uttar Pradesh (UP) Bihar (BH), Uttarakhand (UK)

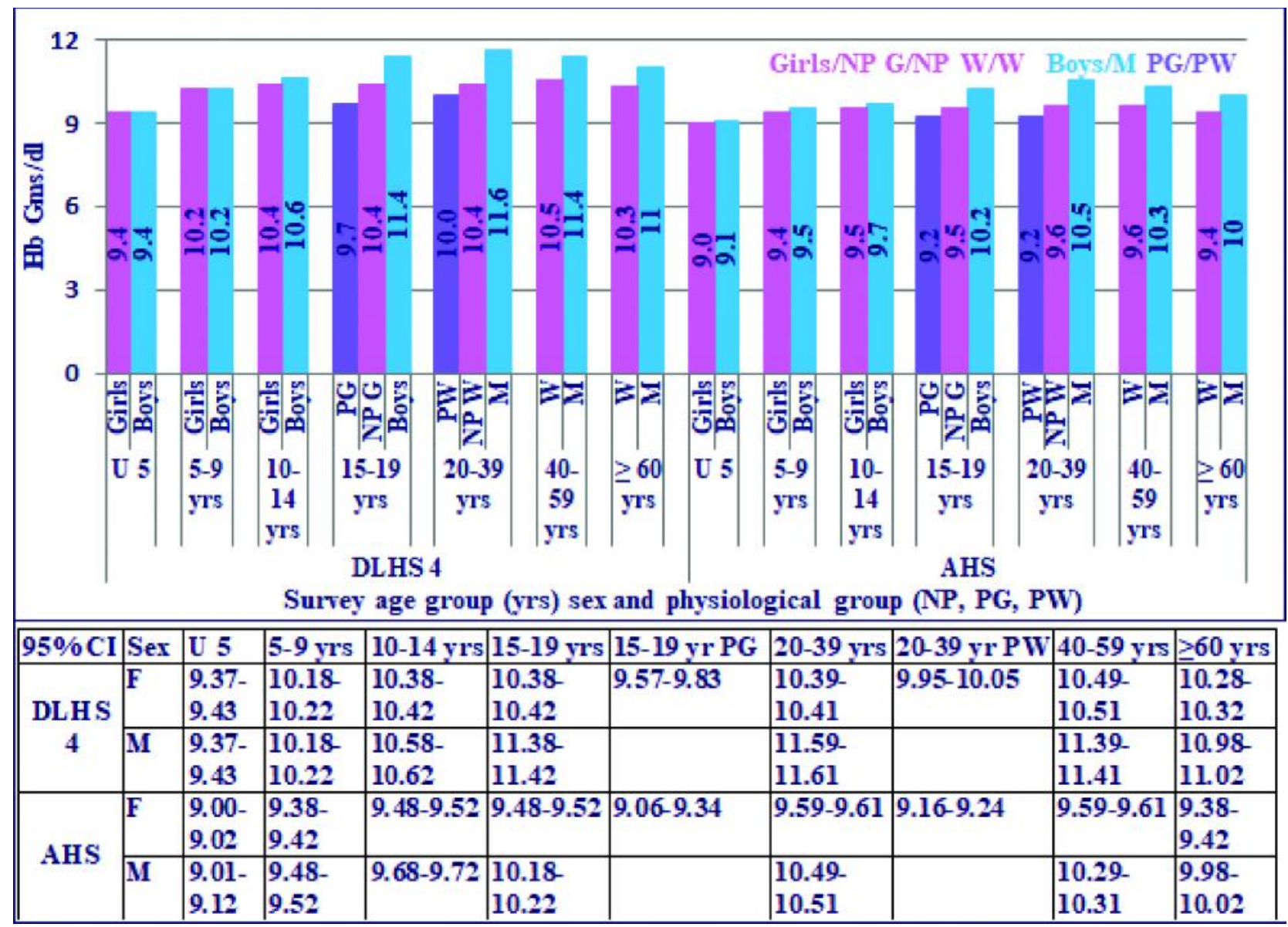

Fig. 9: Mean Hb levels across groups (DLHS 4 \& AHS). U5 under five yr children, PG pregnant girls NP G non-pregnant girls, PW pregnant women, NP W non-pregnant women, W women, $M$ men

mean $\mathrm{Hb}$ with increase in age, both in boys and girls. The mean $\mathrm{Hb}$ values in adults (both men and women) were higher than those in children. The mean $\mathrm{Hb}$ levels in men across all age groups were higher than 
the mean levels in women. The mean $\mathrm{Hb}$ levels were lower in both women and men aged 60 years and above.

In the 0-4 and 5-9 year age groups there was no difference in mean $\mathrm{Hb}$ levels between boys and girls. However, beyond 10 years of age, the mean $\mathrm{Hb}$ levels were higher in boys than in girls.

Pregnant women had mean $\mathrm{Hb}$ levels that were lower than those of non-pregnant women. Adolescent pregnant girls had lower mean $\mathrm{Hb}$ levels than pregnant women in the 20-39 year age group.

The computed mean $\mathrm{Hb}$ levels in preschool children, adolescent girls, pregnant women, men and women in reproductive age were highest in the NFHS series, lower in the DLHS4 survey and AHS -CAB survey and lowest in the DLHS2 (Figs. 1 and 3).

\section{Prevalence of Anaemia}

The prevalence of anaemia and confidence intervals for each age group disaggregated by sex and physiological status are shown in Fig. 10. The prevalence of anaemia across all age and sex groups was lower in the DLHS 4 states as compared to the AHS states. The prevalence was lowest in 15-19 year boys in DLHS 4 states (57.1\%) and highest in men $\leq 60$ years in AHS states $(89.3 \%)$.

The prevalence of anaemia was higher in preschool children as compared to those in the 5-9 year group (even though the $\mathrm{Hb}$ cut-off level for defining anaemia is lower, i.e., $11 \mathrm{~g} / \mathrm{dL}$ in pre-school children as compared to $11.5 \mathrm{~g} / \mathrm{dL}$ in $5-9$ years). In the reproductive age group, prevalence of anaemia was higher in women than in men (even though the $\mathrm{Hb}$ cut-off for defining anaemia in men is $13 \mathrm{~g} / \mathrm{dL}$ as compared to $12 \mathrm{~g} / \mathrm{dL}$ in women). Contrary to the expectation, prevalence of anaemia in pregnant women in the 20-39 year group was lower as compared to the levels in non-pregnant women. The prevalence of anaemia among the elderly (both women and men) was higher than men and women in reproductive age group.

Computed prevalence of anaemia in all the groups were lowest in NFHS series, higher in DLHS4 and AHS CAB surveys and highest in the DLHS 2 (Figs. 2 and 4).

\section{Frequency Distribution of $\mathrm{Hb}$}

The frequency distribution curves for different age groups disaggregated by sex and physiological status are shown in Figs. 11, 12 and 13. In every age group,

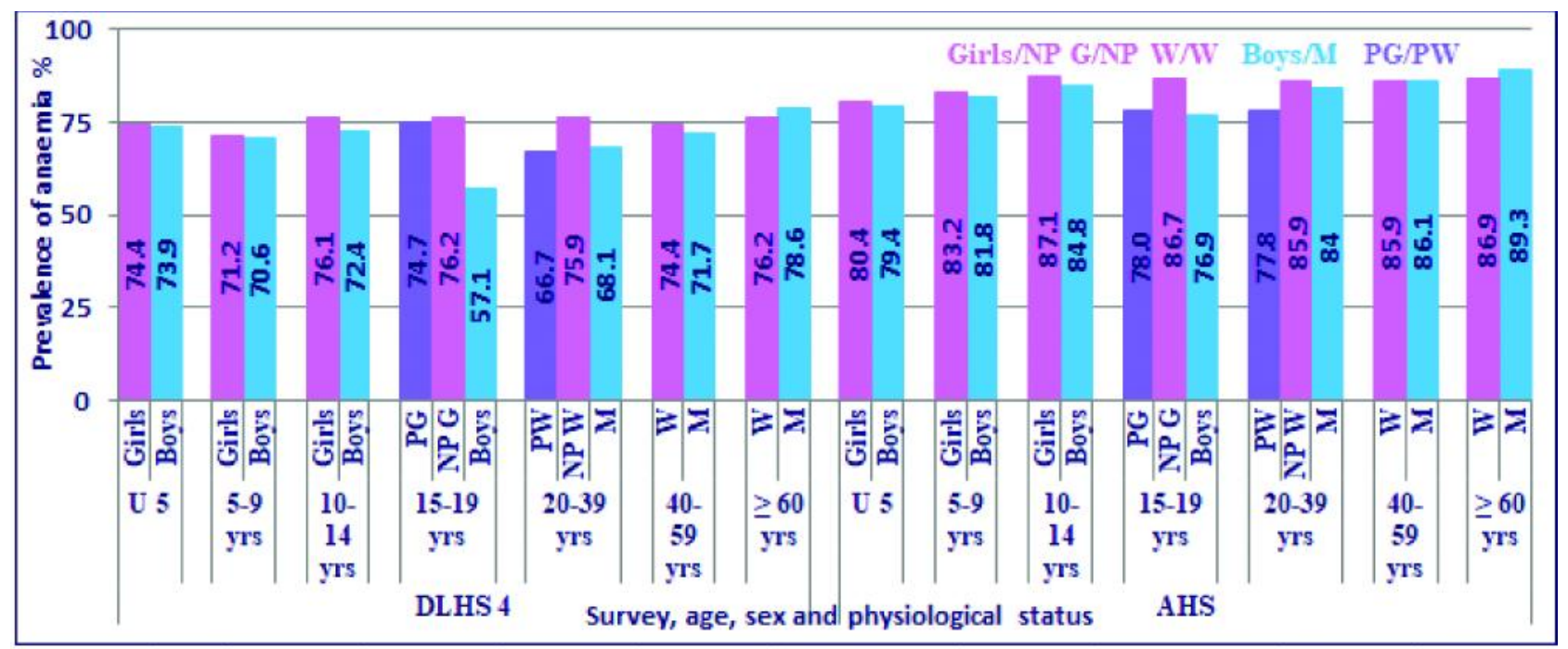

\begin{tabular}{|l|l|l|l|l|l|l|l|l|l|l|}
\hline 95\% CI & Sex & U 5 & $5-9$ yrs & $10-14$ yrs & $15-19$ yrs & 15-19 yr PG & $20-39$ yrs & $20-39$ yr PW & $40-59$ yrs & $\geq 60$ yrs \\
\hline DLHS 4 & F & $73.8-74.9$ & $70.7-71.6$ & $75.7-76.5$ & $75.8-76.6$ & $72.1-77.3$ & $75.7-76.1$ & $65.7-67.7$ & $74.2-74.7$ & $75.9-76.5$ \\
\hline & M & $73.4-74.4$ & $70.1-71.0$ & $72.0-72.8$ & $56.6-57.5$ & & $67.9-68.4$ & & $71.5-72.0$ & $78.2-78.9$ \\
\hline AHS & F & $79.9-80.8$ & $82.9-83.5$ & $86.8-87.3$ & $86.4-87.0$ & $75.5-80.6$ & $85.7-86.1$ & $77.1-78.5$ & $85.7-86.0$ & $86.6-87.1$ \\
\hline & M & $79.0-79.8$ & $81.5-82.1$ & $84.6-85.1$ & $76.6-77.3$ & & $83.8-84.2$ & & $85.9-86.3$ & $89.1-89.6$ \\
\hline
\end{tabular}

Fig. 10: Prevalence of anaemia in different groups (DLHS4 and AHS CAB). U5 under five yr children, PG pregnant girls NP G non-pregnant girls, PW pregnant women, NP W non-pregnant women, W women, $M$ men 

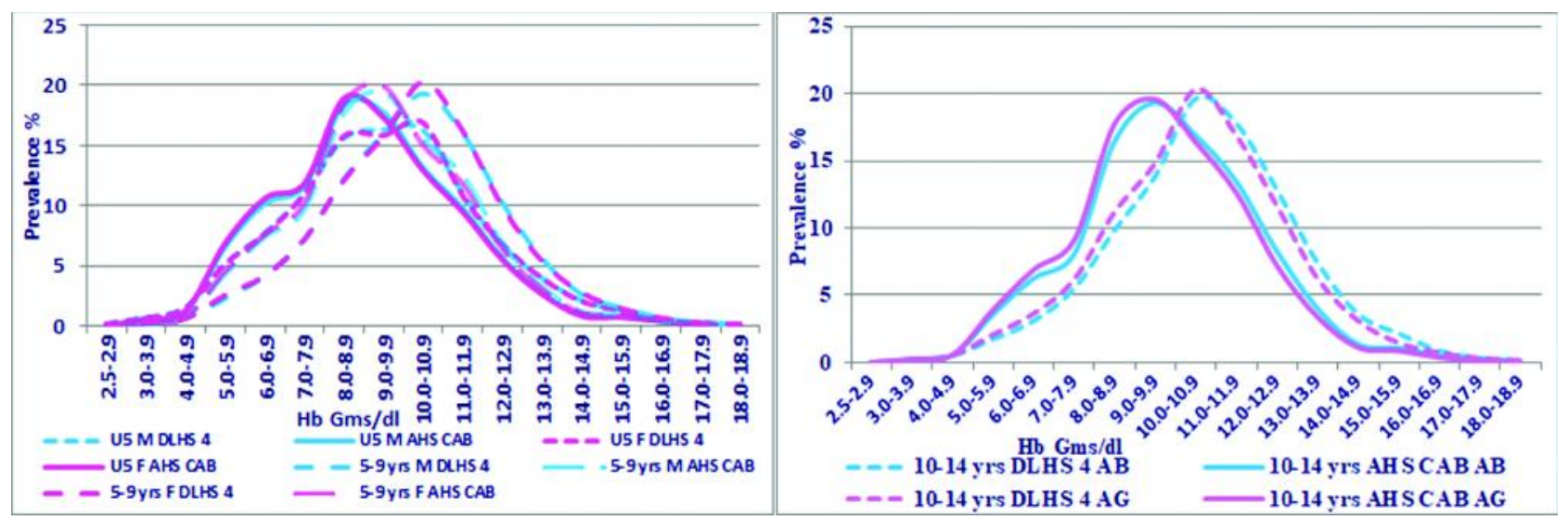

Fig. 11: Frequency distribution of $\mathrm{Hb}$ in 0-14 yr children (DLHS 4 \& AHS). U5 under five yr children M male, F female AB adolescent boys, AG adolescent girls
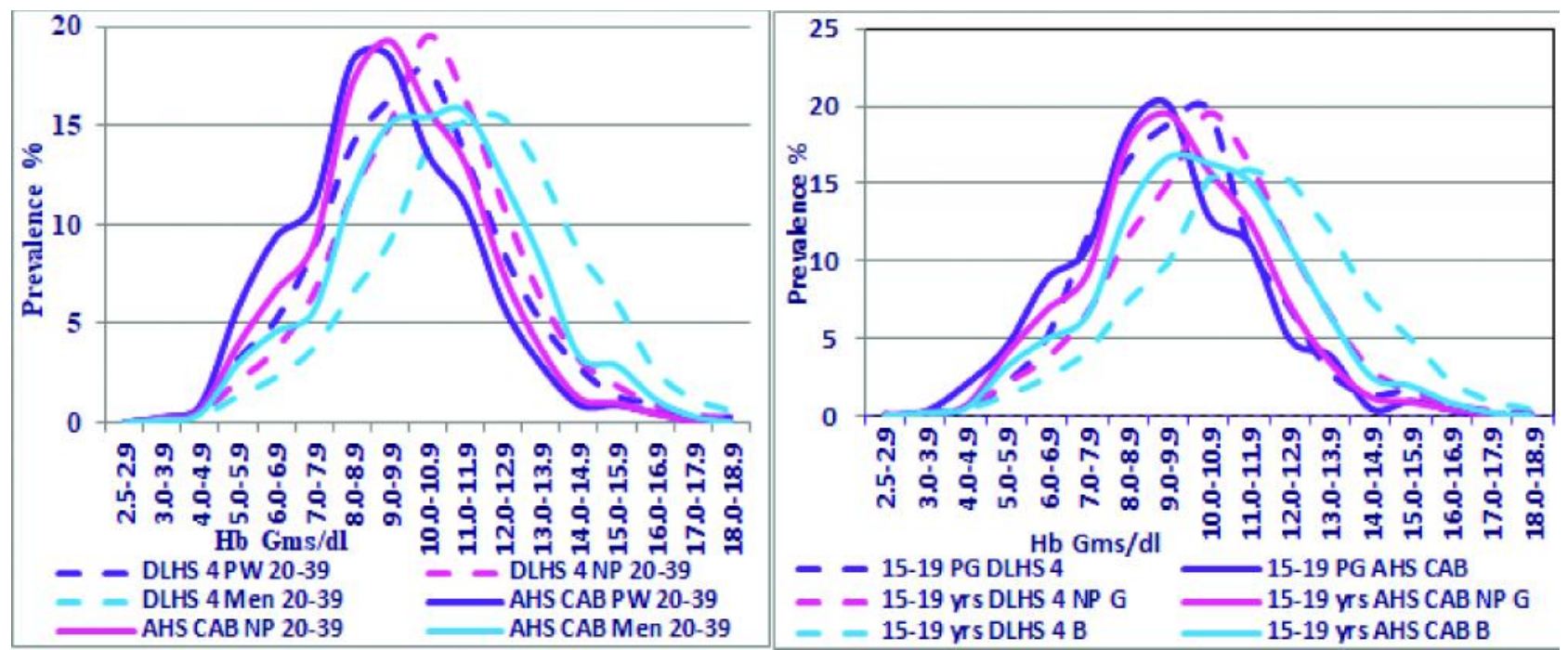

Fig. 12: Frequency distribution of Hb in 15-39 yr age gr (DLHS 4 \& AHS). PW pregnant women, NP W non-pregnant women; B boys
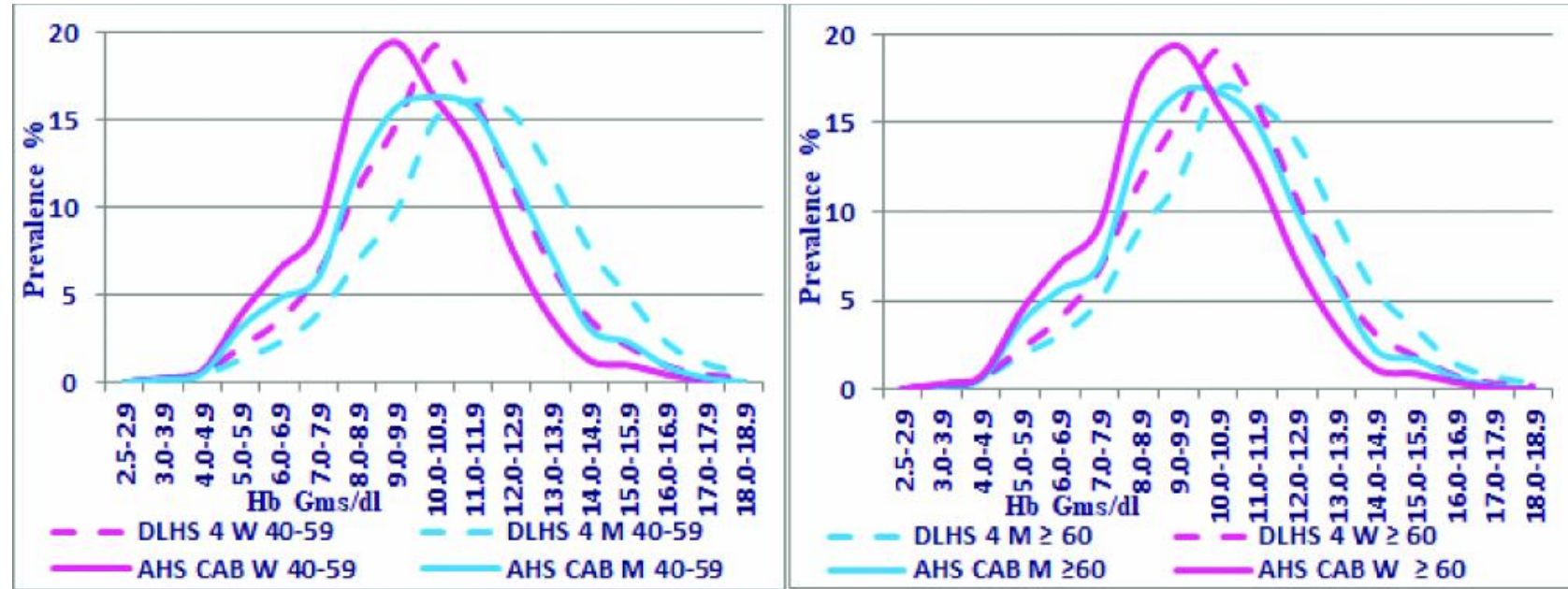

Fig. 13: Frequency distribution of $\mathrm{Hb}$ in $40 \mathrm{yrs} \&$ above (DLHS 4 \& AHS). W women, M men 
the frequency distribution of Hb in DLHS 4 states is to the right of that in the AHS states.

\section{Within Each Survey}

- frequency distributions were similar in boys and girls in the 0-4 years group and in the 5-9 years group the;

- in boys $\leq 10$ years and in men, the frequency distribution curve was to the right of that for girls/women;

- in non-pregnant women, the frequency distribution curve was to the right of the one for pregnant women.

\section{Discussion}

NFHS 2 was the first national survey to report statespecific data on the prevalence of anaemia in pregnant women. The reported prevalence was far lower than the reported prevalence rates from research studies. The lower prevalence of anaemia in NFHS 2 was hailed as the result of successful implementation of the National Anaemia Control programme. The lack of clear and consistent reduction in prevalence of anaemia in pre-school children adolescent girls and pregnant women between NFHS 2, 3 and 4 is now being interpreted as evidence that NACP (NACP 1989, 1991) and National Iron Plus Initiative (NIPI) guidelines (NIPI 2013) are being implemented poorly.

The Nutrition Foundation of India (NFI 2005) undertook a survey in the same villages covered by NFHS 2 in 10 States, using the cyanmethaemoglobin method of $\mathrm{Hb}$ estimation instead of the Hemocue method. The NFI survey showed that the prevalence of anaemia in pregnancy continued to be very high. The Micro-nutrient Survey of the National Nutrition Monitoring Bureau (NNMB 2003) and DLHS 2 showed that the prevalence of anaemia was much higher than those reported by NFHS 2 .

Studies comparing $\mathrm{Hb}$ estimation in the same samples, using Hemocue and the gold standard cyanmethaemoglobin methods, showed that Hemocue under-estimates $\mathrm{Hb}$, and that there was no linear correlation between $\mathrm{Hb}$ values estimated by these two methods (Mohan Ram 2002, Kapoor et al., 2002, Bhaskaram 2003, Pathak 2004). There is no linear correlation between $\mathrm{Hb}$ values estimated by Hemocue and complete blood count. The reported correlation between HemoCue and complete blood count was better $(\mathrm{r}=0.73)$ in the $8.0-11.9 \mathrm{~g} / \mathrm{dL} \mathrm{Hb}$ range and poor $(\mathrm{r}=0.30, \mathrm{r}=0.57)$ when $\mathrm{Hb}$ values were $>12.0 \mathrm{~g} / \mathrm{dL}$ and $<8.0 \mathrm{~g} / \mathrm{dL}$ respectively (Bursey 2015).

The higher mean $\mathrm{Hb}$ levels, lower prevalence of anaemia and lack of reduction in prevalence of anaemia reported in NFHS series are likely to have been due to inaccuracies in $\mathrm{Hb}$ estimation by Hemocue method. In view of the continued very high prevalence of anaemia shown by DLHS 2, efforts were taken up to improve coverage and compliance with IFA supplementation under the Reproductive and Child Health programme.

As compared to DLHS 2, the data from DLHS 4 and AHS CAB (in their respective states) showed asubstantial increase in mean $\mathrm{Hb}$ (Fig. 3), shift to the right in frequency distribution of $\mathrm{Hb}$ (Figs. 5, 6 and 7) and reduction in the prevalence of anaemia in preschool children, adolescent girls and pregnant women (Fig. 4). Despite continued poor coverage under the IFA supplementation programme, there has been an improvement in $\mathrm{Hb}$ status of pre-school children and adolescent girls. Over the last two decades there has been reduction in poverty,improvement in percapita income and household food security; access to health care for malaria and hook worm infestation has improved and there has been a slow but steady decline in under-nutrition rates. It is possible that the observed reduction in anaemia prevalence rates might be part of the overall improvement in nutrition and health status of pre-school children and adolescent girls. In pregnant women, improvement in coverage under antenatal care and IFA supplementation appear to have played an important role, as prevalence of anemia is lower in DLHS states with higher coverage under antenatal care and IFA supplementation.

In India, data from national surveys are widely used for assessing the impact of on-going interventions. It is therefore essential to deploy specially trained personnel with knowledge and skills for data collection and ensure accuracy of measurements by using appropriate equipment, techniques and quality assurance procedures. Data from AHS CAB and DLHS surveys which followed all these norms showed that there has been improvement in mean $\mathrm{Hb}$ levels and reduction in the prevalence of anaemia in the last decade. This 
documentation provided the impetus both for the efforts to improve the coverage and the content of antenatal care and IFA supplementation and investing in national surveys to provide leads for mid-term modifications in the programme.

It is a matter of concern that, despite improvement over a decade, a majority of Indians are anaemic, irrespective of geographical region, age, sex and physiological group (DLHS 42014 and AHS CAB 2015), and that India still continues to be the country with highest prevalence of anaemia in the world. In India, anaemia begins right from infancy, continues into childhood, increases in severity during adolescence in girls, and gets aggravated during pregnancy and among the elderly. The prevalence of anaemia is high not only among under-nourished persons but also in normal and over-nourished individuals. There is an urgent need to use all available interventions to accelerate the pace of improvement in $\mathrm{Hb}$ levels and reduce the prevalence rates of anaemia.

Data from NNMB surveys (NNMB 2003, 2012) indicate that, in India, intake of micro-nutrient rich vegetables is low; iron and folate intakes are half or lower as compared to the requirements. The estimated average intake of iron from Indian diets ranges from 10-15 mg per day. This intake is not much lower than the iron intake in developed countries. But the bioavailability of iron from phytate and fibre-rich Indian diets is only $5-8 \%$, whereas bio-availability of haem iron from animal food is over $40 \%$.

Dietary diversification, with increase in the consumption of vegetables, especially green leafy vegetables which are the richest source of iron and folate in a vegetarian diet, is essential for sustainable improvement in iron and folate intake. Increase in vegetable consumption also reduces the risk of overnutrition and non-communicable diseases. Indian farmers responded to the initiatives under the National Horticultural Mission (NHM 2007) and there has been a substantial increase in vegetable production in India. However, farmers face economic constraints because of high wastage and the cyclical glut in vegetables. Consumers cannot buy and consume larger quantities of vegetables because of the high cost. Investments are urgently needed in grading, storage, processing and marketing of vegetables, which will make horticulture remunerative for the farmer and provide vegetables at affordable cost to the consumer.

Iron is essential for $\mathrm{Hb}$ synthesis. Because of poor bio-availability of iron from Indian diets it is difficult to meet the RDA (ranging from $17 \mathrm{mg}$ in men, to $38 \mathrm{mg}$ in pregnant women) for Indians through dietary diversification alone. The World Health Organisation (WHO) (WHO 2006) advocates food fortification with iron for sustained improvement in $\mathrm{Hb}$ levels in countries with low iron intake. Given the widespread iron deficiency in Indians, food fortification offers a ready, relatively inexpensive and sustainable method of increasing the iron intake without altering dietary habits. The National Institute of Nutrition, Hyderabad, has developed technology for iron-fortified iodised salt (double fortified salt DFS) and has transferred the technology to the industry. Food Safety and Standards Authority of India (FSSAI) has approved two technologies for manufacture of DFS. The major advantage of the use of DFS is that salt is used by all segments of the population, is unlikely to be over-used, and is relatively inexpensive (DFS cost is higher by Rs. $1-3 / \mathrm{kg}$ as compared to iodised salt). The use of DFS has been made mandatory in hot cooked meals under the Mid-Day Meal (MDM) and Integrated Child Development Service (ICDS) programmes. Some states are currently providing DFS through the Public Distribution System (PDS) in selected districts. Centralised production and preexisting programmes for fortification of salt with iodine offer a very ready platform to launch iron-fortified iodised salt. Once the production, distribution and sale of DFS have been scaled up, it might be possible to make DFS mandatory for human consumption, achieve sustained, population-wide increase in the intake of iodine and iron, and thereby combat IDD and anaemia.

The use of DFS in the daily diet increases iron intake by $10 \mathrm{mg} /$ day; consistent use of DFS has been shown to improve Hb level by $0.5 \mathrm{~g} /$ year (Sivakumar et al., 2001). Dietary diversification and DFS together can improve $\mathrm{Hb}$ levels by $0.5-0.7 \mathrm{~g} /$ year and, when sustained over a decade, can reduce the prevalence of anaemia substantially. The improvement in $\mathrm{Hb}$ response is higher in the iron-deficient and anaemic persons. Undoubtedly universal use of DFS is the most economic, effective and sustainable method of improving iron intake and $\mathrm{Hb}$ levels in Indians. However, the pace of increase in $\mathrm{Hb}$ by use of DFS 
is slow; more rapid improvement in $\mathrm{Hb}$ is needed in vulnerable groups such as pre-school and school children.

Based on clinical evidence and available epidemiological data, India initiated iron and folic acid (IFA) supplementation programmes to address anaemia in these two groups. Research studies have shown that, in situations where prevalence of anaemia is high, daily iron folic acid supplementation in preschool children, adolescents and women for three months or longer resulted in improvement in mean $\mathrm{Hb}$ (of about 0.5 to $1 \mathrm{~g} / \mathrm{dL}$ and ferritin levels (Thompson 2013, Pasricha 2013). Improvement in $\mathrm{Hb}$ was higher with daily supplementation as compared to bi-weekly or weekly supplementation, but compliance with daily supplementation was more difficult to maintain on a long-term basis. Given the operational difficulty in daily supervised administration of iron folic acid tablets to adolescent girls, the earlier WHO guidelines had recommended weekly IFA supplementation (WHO 2011). However, such intermittent supplementation has to be continued throughout the year and year after year. Year round supervised weekly IFA supplementation may pose problems in many settings. The current WHO guidelines (WHO 2016) recommend daily IFA supplementation for 3 months every year in settings where prevalence of anaemia is $40 \%$ or higher. Not all anaemic persons become non-anaemic after three months of daily supplementation;once supplementation is stopped some of those who did become nonanaemic may become anaemic (Lynch 2000, Allen 2002). Supplementation programmes are expensive because the personnel are required for counselling, distributing supplements and monitoring to improve compliance.

In 2015, the Government of India initiated the nationwide Weekly Iron Folic Acid Supplementation (WIFS) programme for pre-school and school-age children. The meagre reports available suggest that under the programme, coverage of pre-school children was sub-optimal in many states, because of erratic supply of IFA syrup and problems in administering it. Coverage under the programmeis higher in school children than that in pre-school children; but troublesome side effects such as abdominal pain and nausea occur in about $10 \%$ of the children and come in the way of continued coverage. Nutrition education assuring the children, parents and teachers that these side-effects are transient and have no adverse effect on the children's health might improve compliance and continuation. However, both global and Indian studies have shown that it is difficult to sustain yearround supplementation programmes year after year. This is partly due to the fact that anaemia itself is asymptomatic, side effects with IFA supplementation are obvious and improvement in anaemia is not perceptible to the person receiving the supplement.

Though more than $20 \%$ of pregnant women experience side effects, the coverage and compliance with IFA supplementation is higher because:

- $\quad$ pregnancy is a clearly defined short period;

- IFA supplementation has been an integral component of antenatal care;

- $\quad$ Pregnant women know that maternal anaemia is associated with higher maternal morbidity, lower birth weight and higher infant mortality,

- women will do whatever they can to improve the health of their offspring.

Data from all the surveys indicate that there was some improvement in coverage under iron-folic acid supplementation in pregnant women (NFHS 3 $15.2 \%$, NFHS $430.3 \%$ ). The prevalence and severity of anaemia in pregnant women were lower in States with higher coverage under antenatal care and IFA supplementation. Improvement in content and coverage of antenatal care and increase in number of women who have taken IFA supplementation, have been the major factors responsible for the improvement in $\mathrm{Hb}$ status in pregnant women. It is noteworthy that both in DLHS and AHS states, the prevalence of anaemia in pregnant women is lower than in non-pregnant women; this is most likely to be due to the impact of IFA supplementation.

India still ranks the first in terms of maternal deaths due to anaemia; maternal anaemia is one of the major factors associated with low birth weight. This is partly because screening for anaemia and appropriate management envisaged in the national (NACP 1989, NIPI 2013) guidelines have not been widely implemented. In order to achieve rapid improvement in $\mathrm{Hb}$ levels within the limited time available during pregnancy and to prevent the adverse 
consequences of anaemia on the mother-child dyad, it is imperative that the 'test and treat' strategy envisaged in the NIPI guidelines for management of anaemia is fully operationalised. NACP, as well as the NIPI envisaged the screening of all pregnant women for anaemia using either the $\mathrm{Hb}$ colour scale or Sahli's haemoglobinometer because these have been provided under the programme right up to subcentres across the country. Neither of these is accurate enough to grade anaemia or correctly assess the impact of treatment. The recent WHO antenatal care guidelines (WHO 2016) do not advocate the use of $\mathrm{Hb}$ colour scale for screening for anaemia. India should stop using inaccurate $\mathrm{Hb}$ colour scale and Sahli's haemoglobinometer and start using cyanmethaemo-globin method for accurate estimation of $\mathrm{Hb}$. This will enable clinicians to implement NIPI guidelines for prevention and management of anaemia and monitor improvement in $\mathrm{Hb}$ levels during treatment. Women will comply with treatment because they can understand the rationale of the treatment protocol and see improvement in $\mathrm{Hb}$. Introducing accurate $\mathrm{Hb}$ estimation can thus trigger compliance with a virtuous treatment cycle and enable the country to rapidly achieve substantial reduction in anaemia and in its adverse consequences in pregnancy.

\section{References}

Agarwal K N, Agarwal D K and Sharma A (2005) Anaemia in pregnancy-Interstate differences Nutrition Foundation of India New Delhi

Allen L H (2002) Iron supplements: scientific issues concerning efficacy and implications for research and programs The Journal of nutrition 132 813S-819S

Angeles-Agdeppa I, Schultink W, Sastroamidjojo S, Gross R and Karyadi D (1997) Weekly micronutrient supplementation to build iron stores in female Indonesian adolescents The American Journal of clinical nutrition 66 177-183

Bhaskaram P, Balakrishna N, Radhakrishna K V and Krishnaswamy K (2003)Validation of hemoglobin estimation using Hemocue The Indian Journal of Pediatrics 70 25-28

Bursey M, Curtis K, Gibson M, Gibson R, Xu H and Lyon M (2013) HemoCue versus Complete Blood Count for

\section{Summary and Conclusions}

Data from large-scale national surveys have shown that, over the last decade, there has been some improvement in coverage under IFA supplementation programme in pregnant women, reduction in the prevalence of anaemia across all states and in preschool children adolescent girls and pregnant women. However, the country still has the highest prevalence of anaemia in the world. Low intake of micro-nutrientrich vegetables and poor bio-availability of iron from Indian diets are the major factors responsible for the continued high prevalence of anaemia in the country. The three-pronged strategy of increasing iron intake in all households through dietary diversification and use of iron-fortified iodized salt, IFA supplementation to vulnerable groups (pre-school, and school age children) and testing for, detecting and treating anaemia in pregnant women will accelerate the pace of reduction in anaemia and enable the country to achieve the SDG target for reduction in anaemia.

\section{Acknowledgements}

The authors acknowledge International Institute of Population Sciences (IIPS) for providing raw data of DLHS 2 and 4, Ministry of Health and Family Welfare, Government of India for providing the raw data of AHS CAB and Demographic and Health Survey for providing the raw data of NFHS 2, 3 and 4.

Hemoglobin Measurement in Adults With Vaso-occlusive Crisis Due to Sickle Cell Disease Annals of Emergency Medicine 62 S40-S41

Duque X, Martinez H, Vilchis-Gil J, Mendoza E, FloresHernández S, MoránS and Mera R M (2014) Effect of supplementation with ferrous sulfate or iron bis-glycinate chelate on ferritin concentration in Mexican schoolchildren: a randomized controlled trial Nutrition journal 13 71-81

International Institute of Population Sciences (IIPS) (1999) National Family Health Survey (NFHS) 2 http:// www.rchiips.org/nfhs/nfhs2.shtml, accessed on June $2^{\text {nd }}$, 2018

IIPS (2006) National Family Health Survey (NFHS) 3 http:// www.rchiips.org/nfhs/nfhs 3 .shtml, accessed on June $2^{\text {nd }}$, 2018

IIPS (2015) National Family Health Survey (NFHS) 4 Fact Sheets http://www.rchiips.org/nfhs/factsheet_NFHS-4.shtml, 
accessed on June $2^{\text {nd }}, 2018$

IIPS (2005) DLHS- 2 District Level Household and Facility Survey http://www.rchiips.org/PRCH-2.html, accessed on June $2^{\text {nd }} 2018$

IIPS (2014) DLHS-4 District Level Household and Facility Surveyhttp://www.rchiips.org/DLHS-4.html, accessed on June $2^{\text {nd }} 2018$

Kalaivani K (2009) Prevalence \& consequences of anaemia in pregnancy Indian J Med Res 130 627-33

Kapoor S K, Kapil U, Dwivedi S N, Anand K, Pathak P and Singh P (2002) Comparison of HemoCue method with cyanmethemoglobin method for estimation of hemoglobin Indian pediatrics 39 743-746

Kozuki N, Lee AC and Katz J (2013) Child Health Epidemiology Reference Group. Moderate to severe, but not mild, maternal anaemia is associated with increased risk of smallfor gestational-age outcomes J Nutr 142 358-62

Lynch S R (2000) The potential impact of iron supplementation during adolescence on iron status in pregnancy The Journal of nutrition $130448 \mathrm{~S}-451 \mathrm{~S}$

Maternal Health Task Force World Health organisation (WHO) (2016) Improving Quality of Antenatal Care: New Guidelines From the World Health Organization T.H. Chan School of Public Health; Harvard Boston: https:// www.mhtf.org/2016/11/10/, accessed on June $2^{\text {nd }} 20,2018$

Ministry of Health and Family Welfare (MoHFW) (1970) Prophylaxis against nutritional anaemia among mothers and children Technical Information, MCH No. 1 New Delhi

MoHFW (1989) Report of the meeting on Prevention and control of nutritional anaemias Government of India and UNICEF New Delhi

MoHFW (1991) Policy on control of nutritional anaemia MoHFW New Delhi

MoHFW (2013) Guidelines for Control of Iron Deficiency Anaemia Government of India, New Delhi. http:// www.pbnrhm.org/docs/iron_plus_guidelines.pdf, accessed on June $2^{\text {nd }}, 2018$

Mohan Ram M, Ramana Rao G V and Sastry J G (2002) A comparative study on prevalence of anaemia in women by cyanmethemoglobin and Hemocue methods Indian $J$ Community Med 27 58-61

National Nutrition Monitoring Bureau (NNMB) Technical Report No. 22 (2003) Prevalence of Micronutrient Deficiencies Hyderabad: National Institute of Nutrition; http://www.nnmbindia.org/NNMB\%20MND\%20 REPORT\%202004-Web.pdf accessed on June 2 $2^{\text {nd }}, 2018$
NNMB (2012) National Nutrition Monitoring bureau repeat surveys - nnmbindia.org/1_NNMB_Third_Repeat_Rural_ Survey_Technicl_Report_26.pdf accessed on 22.6. 2018

National Horticulture Mission (NHM) (2007) pibmumbai.gov.in/ English/PDF/E0000_SH39PDFaccessed on 26.6.2018

Pathak P, Kapoor S K, Dwivedi S N, Singh P and Kapil U (2004) Comparison of hemoglobin estimates from filter paper cyanmethemoglobin and HemoCue methods Indian Journal of Community Medicine 29149

Pasricha S R, Hayes E, Kalumba K and Biggs B A (2013) Effect of daily iron supplementation on health in children aged 423 months: a systematic review and meta-analysis of randomised controlled trials The Lancet Global Health 1 e77-e86

Registrar General of India (2015) Annual Health Survey: CAB Component http://www.censusindia.gov.in/2011census/ hh-series/cab.html, accessed on June $2^{\text {nd }}, 2018$

Sharma A, Patnaik R, Garg S and Ramachandran P (2008) Detection \& management of anaemia in pregnancy in an urban primary health care institution Indian J Med Res $12845-51$

Sivakumar B, Brahmam G N V, Madhavan Nair K, Ranganathan S, Vishnuvardhana Rao M, Vijayaraghavan K and Kamala Krishnaswamy (2001) Prospects of fortification of saltwith iron and iodine British Journal of Nutrition 5 S167S173

Stevens G A, Finucane M M, De-Regil L M, Paciorek C J, Flaxman S R and Branca F (2013) Global, regional, and national trends in haemoglobin concentration and prevalence of total and severe anaemia in children and pregnant and non-pregnant women for 1995-2011: A systematic analysis of population-representative data The Lancet Global Health 1 e16-e25

Steer PJ (2000) Maternalhemoglobin concentration and birth weight The American journal of clinical nutrition 71 1285S $1287 \mathrm{~S}$

Thompson J, Biggs B A and Pasricha S R (2013) Effects of daily iron supplementation in 2-to 5-year-old children: systematic review and meta-analysis Pediatrics 131 739. 753

WHO (2006) Guidelines on food fortification with micronutrients http://www.who.int/nutrition/publications/guide_food_ fortification_micronutrients.pdf accessed on 28.1.2018

WHO (2011) Intermittent iron and folic acid supplementation in menstruating women http://www.who.int/elena/titles/ guidance_summaries/iron_women/en/ accessed on 28.1.2018 
WHO (2015) The global prevalence of anaemia $2011 \mathrm{http}: / /$ www.who.int/nutrition/publications/micronutrients/ global_prevalence_anaemia.../en/, accessed on June $2^{\text {nd }} 2018$

WHO (2016) Guideline daily iron supplementation to infants and children www.who.int/nutrition/publications/.../ guidelines/daily_iron_supp_childrens/en accessed on June 2nd 2018
WHO (2016) Daily iron supplementation in adult women and adolescent girls www.who.int/nutrition/publications/.../ guidelines/daily_iron_supp_womenandgirls/en/accessed on 28.1.2018. 